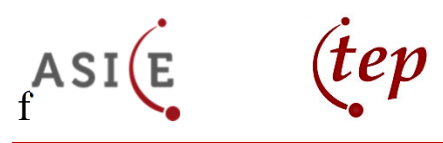

ARTÍCULO DE INVESTIGACIÓN / ORIGINAL RESEARCH PAPER

\title{
Los pilares de la lengua. El paso del tiempo y las columnas lingüísticas ${ }^{1}$
}

\section{The language pillars. Time passing through and language columns}

\author{
Dolors Poch Olivé \\ Universitat Autònoma de Barcelona, Barcelona, España \\ dolors.poch@uab.cat
}

\section{ACCESO ABIERTO / OPEN ACCESS}

Cita: Poch Olivé, Dolors (2020). Los pilares de la lengua. El paso del tiempo y las columnas lingüísticas. Textos en Proceso, 6(2), pp. 146161.

https://doi.org/10.17710/tep.2020.6. 2.10poch

\section{Editoras: Susana Guerrero Salazar y Carmen Marimón Llorca}

Recibido: $15 / 10 / 2020$

Aceptado: 20/11/2020

Conflicto de intereses: La autora ha declarado que no posee conflicto de intereses.

Copyright: @ Dolors Poch Olivé. Esta obra está bajo licencia Creative Commons Reconocimiento 4.0

\section{Resumen}

El presente trabajo tiene como objetivo analizar las columnas sobre la lengua escritas por Fernando Araujo y Javier Marías, el primero de ellos a caballo entre los siglos XIX y XX y el segundo entre los siglos XX y XXI. Como se verá, aunque les separa una distancia de cien años, los dos autores comparten las mismas preocupaciones por la corrección lingüística e, incluso, tratan los mismos problemas en sus colaboraciones periodísticas. El artículo realiza una reflexión general sobre el efecto del paso del tiempo sobre las columnas lingüísticas.

Palabras clave: columnas sobre la lengua, Fernando Araujo, Javier Marías.

\begin{abstract}
This paper aims to analyze the columns about the language written by Fernando Araujo and Javier Marías, the first of them between the 19th and 20th centuries and the second between the 20th and 21 st centuries. As will be seen, although they are separated by a distance of one hundred years, the two authors share the same concerns about linguistic correctness and even treat the same problems in their journalistic collaborations. The paper reflex on the effect of the passage of time on linguistic columns.
\end{abstract}

Keywords: columns on language, Fernando Araujo, Javier Marías.

\footnotetext{
${ }^{1}$ La presente investigación ha sido posible gracias a la financiación del proyecto El español de Cataluña en los medios de comunicación orales y escritos (FF12016-76118-P), junto al apoyo de la Generalitat de Catalunya para el Grupo de Investigación Consolidado "Grup de Lexicografia i Diacronia" (núm. de referencia 2017 SGR 1251).
} 


\section{Introducción}

Una lengua puede compararse con un edificio que posee una estructura determinada que se apoya en unas paredes maestras, unas columnas y unos pilares. Está, por tanto, sostenido por diferentes elementos de apoyo. Siguiendo con esta metáfora, puede considerarse que existen instituciones que se ocupan de que la estructura esté siempre en buen estado, de que no se produzcan grietas en las paredes maestras, de que las columnas resistan bien las diferentes presiones a las que la estructura está sometida. En el caso del español, esta labor la realizan no solamente la Real Academia Española sino el conjunto de las academias de los distintos países hispanohablantes, ASALE, que velan por cuidar la lengua en su unidad y en su diversidad. La preservan de los peligros que podrían atacar la estructura del edificio respetando a la vez la diversidad en los usos que presentan las distintas variedades. Otros agentes intentan también colaborar en esta empresa: las columnas periodísticas de carácter lingüístico. Estos textos no desempeñan una misión tan fundamental como la de las instituciones, pero están siempre alertas a los usos de los hablantes para llamar la atención sobre ellos si se alejan del cuidado y la corrección. Las columnas sobre la lengua tienen la voluntad de funcionar como pilares del edificio, como soportes en los cuales pueda también apoyarse su estructura para evitar el deterioro. Por todo ello, el título de este trabajo alude a la labor de preservación de la lengua que este tipo de colaboraciones en la prensa realiza habitualmente.

De estas observaciones se desprende, como primer aspecto importante de carácter general, que las columnas periodísticas sobre el lenguaje constituyen una fuente importantísima de datos para el estudio de los usos propios de los hablantes, tanto desde el punto de vista sincrónico como desde el punto de vista diacrónico. Ofrecen una instantánea de cómo se habla en un período determinado del tiempo y, por tanto, permiten realizar el seguimiento diacrónico de las variaciones que puede sufrir una determinada lengua con el paso de los años. En un número monográfico como el presente es ocioso destacar las importantísimas aportaciones efectuadas por el grupo de investigación METAPRES ${ }^{2}$ al estudio del lenguaje desde esta perspectiva. Los trabajos de este equipo han inspirado, además, no pocas publicaciones de otros investigadores no especializados en el tema que han visto la importancia que podían tener para sus propios trabajos los datos que ofrecen las columnas de prensa sobre el lenguaje.

También desde una perspectiva general, los usos del lenguaje se suelen presentar en ellas "negativamente", es decir, funcionan como una suerte de Appendix Probi en las que el autor analiza y rechaza una forma determinada de decir algo, a veces con virulencia, para inducir a los lectores a emplear los buenos usos y la corrección. Marimón (2019a, p. 17) señala a este respecto:

Se caracterizan porque sus autores -no necesariamente con conocimientos lingüísticos- expresan en ellas juicios rigurosos que, sobre los usos del lenguaje, realizan sus contemporáneos [...] suponen siempre un posicionamiento ideológico sobre la lengua: pureza, variación, buen estilo, neologismos, anglicismos, etc., que se plantea en términos de trasgresión de una norma de corrección idiomática que, en muchos casos [...] está frecuentemente relacionada con algún tipo de norma social que el firmante considera en peligro.

\footnotetext{
${ }^{2}$ https://metapress.azurewebsites.net/index.html
} 
Es normal que así sea dado que el objetivo de estas colaboraciones en la prensa es velar por la corrección y por la normativa, y la normativa no es una cuestión científica, sino que, como indica la autora, es un posicionamiento ideológico pues el prestigio lingüístico está determinado por razones de prestigio social.

En la prensa del siglo XIX son ya frecuentes las columnas de este tipo que, además, eran muy bien recibidas por los lectores y daban pie a fuertes polémicas en el seno de la sociedad en función de las opiniones expresadas por sus autores (Poch, 2018). La tradición continúa a lo largo de todo el siglo XX (véase, por ejemplo, Alcoba, 2018 y Marimón, 2019b) y llega hasta nuestros días e, igual que hace ciento cincuenta años, son enormemente populares y las opiniones de los columnistas siguen constituyendo un foco importante de atención para los lectores que disfrutan con las discusiones y quieren también opinar sobre las cuestiones tratadas porque el lenguaje se siente como una propiedad de todos los hablantes. Y así es, lógicamente, pues quien hace caer en desuso determinadas palabras o expresiones o quien las consolida definitivamente y les concede un lugar en la estructura del edificio son los hablantes en su conjunto.

Este trabajo se propone analizar las columnas sobre la lengua de dos autores muy conocidos (cada uno en su época), Fernando Araujo y Javier Marías, firmantes de numerosas publicaciones de este tipo y tiene la finalidad de estudiar los siguientes aspectos de sus trabajos: ¿Han cambiado, con el paso del tiempo, las cuestiones tratadas en las columnas o se siguen discutiendo los mismos aspectos? ¿Presenta similitudes la posición desde la que cada uno de ellos defiende sus opiniones? y ¿Cuál es el tono del discurso argumentativo utilizado por ambos columnistas? Las respuestas a estas cuestiones proporcionarán información sobre las columnas lingüísticas escritas a un siglo de distancia y las analizarán desde la perspectiva de su relación con la tradición de estos escritos y la posible modernidad que pueden aportar las columnas del siglo XXI. O, dicho en otras palabras: ¿Los pilares de la lengua se parecen a pesar de los años que las separan o bien el paso del tiempo ha cambiado sus características?

Como se detallará a continuación, en el caso de Fernando Araujo se han analizado todas sus colaboraciones en la revista La España Moderna (1889-1914) y en el caso de Javier Marías se ha estudiado el conjunto de textos que están editados en el volumen Lección pasada de moda (2012).

\section{Fernando Araujo y La España Moderna}

La España Moderna fue una revista cultural editada y publicada por José Lázaro Galdiano entre 1889 y 1914. Señala Raquel Asún (1980, p. 133) que fue la única publicación de finales del siglo XIX y comienzos del XX que se consideró equiparable a las iniciativas del mismo carácter existentes en Europa y que Lázaro Galdiano la concibió a imagen y semejanza de la Revue des deux Mondes. Como esta última, constaba de diversas secciones que tocaban temas de actualidad y contaba con colaboradores de reconocido prestigio en los diversos ámbitos de la cultura.

La sección Revista de Revistas se inició en agosto de 1898 y estuvo a cargo de Fernando Araujo, salmantino, catedrático de francés de instituto, que había ocupado la cátedra de dicha materia en un instituto de Toledo y en 1896 obtuvo plaza en el Instituto Cardenal Cisneros de Madrid (Poch, 2018). Araujo era un prolífico erudito entre cuyas obras cabe destacar una Gramática de la Lengua 
Francesa (Lepinette, 2000 y 2009) y el primer tratado de Fonética Española, publicado en 1894 (Poch, 2015), amén de numerosas colaboraciones en la prensa, una historia de Alba de Tormes y un volumen sobre la vida cotidiana en Salamanca en el siglo XIX (García García, 2014).

La sección Revista de Revistas se compone, en cada número de La España Moderna, de una serie de comentarios que suelen ocupar entre treinta y cuarenta páginas en los que el autor trata cuestiones relacionadas con las disciplinas que menciona en la presentación de la sección: artes, ciencias sociales, pedagogía, psicología, heráldica, higienismo, criminología, ciencias naturales, ciencias ocultas, costumbres, etc. Dichos comentarios suelen partir de informaciones de carácter científico-divulgativo publicadas por revistas preferentemente extranjeras. Araujo presenta la cuestión tratada y, a continuación, facilita la información e incluye siempre una reflexión sobre la incidencia o la representación del problema en la sociedad española o en sociedades vecinas. Es decir, introduce sus propios elementos de juicio referidos a los contenidos que presenta. Con el paso del tiempo, el autor se aleja de sus planteamientos iniciales para verter, en sus comentarios, casi exclusivamente sus propias opiniones sobre las cuestiones que trata y, con mucha mayor frecuencia, lo hace en las observaciones dedicadas a cuestiones lingüísticas. Hay que señalar especialmente las virulentas diatribas que Araujo lanza contra tirios y troyanos cuando trata temas relacionados con el uso correcto o incorrecto de la lengua.

La postura de Araujo es, siempre, la del normativista a ultranza y su discurso se caracteriza no solamente por el punto de vista que defiende sino también por la virulencia con la que lo hace. Como se verá, las colaboraciones de Araujo en La España Moderna evolucionan, con el tiempo, hacia artículos que discuten usos erróneos del español de España y de América. Es probable que este giro en la orientación de la sección condujera a generarle simpatías y a aumentar el número de sus lectores. Parece que las discusiones sobre "lo correcto" y "lo incorrecto" interesaban al público del siglo XIX de forma parecida al interés que suscitan actualmente. Algunas polémicas que, sobre estos temas, suelen aparecer habitualmente en la prensa constituyen, en pleno siglo XXI, una buena muestra de ello. Las contribuciones sobre aspectos normativos comienzan a aparecer a partir de 1907 y los años que van desde 1908 hasta 1910 son los que registran un mayor número de artículos sobre estos temas alejados, desde luego, de los objetivos que se marcaba Araujo en la inauguración de su sección. Buen ejemplo de ellos son los comentarios titulados Galicismos a granel (enero 1908, n. ${ }^{\circ} 229$ ) (ya citado), ¿Análisis química o análisis químico? (abril 1908, n. ${ }^{\circ}$ 232) o ¿Verisímil o verosímil? (julio 1909, n. ${ }^{\circ}$ 247). Este tipo de comentarios se sitúan lejos del propósito de conseguir que la sección Revista de Revistas constituyera "un Anuario de la vida intelectual" como indicaba el propio Araujo en 1898.

El interés por parte de los lectores de finales del siglo XIX y comienzos del siglo XX por cuestiones normativas es señalado también por García García (2014, p. 255) quien indica que eran frecuentes las referencias a la Revista de Revistas en las publicaciones de la época, de forma que la sección adquirió enorme importancia y popularidad y afirma que ello contribuyó a que se afianzara una relación de amistad entre Araujo y Lázaro:

José Lázaro Galdiano le permite las referencias a sus propias obras y a su vida privada (referencias a su sobrina, a su gato, a sus recuerdos infantiles, anécdotas, etc.) [...] 
que se salían de la rigidez con que trataba a otros colaboradores [...] se lo permite por amistad, favores e intereses y el salmantino fue extremadamente fiel a su compromiso.

La España Moderna puede consultarse en la Hemeroteca Digital de la Biblioteca Nacional ${ }^{3}$. Para este estudio se ha procedido al vaciado de las columnas lingüísticas publicadas por Fernando Araujo entre los años indicados. El corpus recogido comprende un total de 70 artículos que se detallan la Tabla 1 del apéndice (en la columna de la izquierda figura la localización del artículo en la revista y, en la de la derecha el título de cada columna).

Como se puede apreciar, incluso una lectura rápida de los títulos (por ejemplo, "Galicismos a granel" o "Transgresiones prosódicas") pone claramente de manifiesto que la corrupción de la lengua constituye la columna vertebral de las reflexiones de Araujo sobre los usos lingüísticos.

\section{Javier Marías y Lección pasada de moda}

Javier Marías no necesita presentación actualmente pues es uno de los escritores vivos más importantes en lengua española y no es necesario citar aquí su extensa obra narrativa. Su trayectoria como columnista de prensa ha sido estudiada por Steenmeijer (2006), trabajo en el que su autor traza el itinerario del escritor como colaborador en la prensa relacionándolo con su trayectoria novelística. El escritor inició sus colaboraciones en los rotativos cuando ya había publicado varios textos narrativos y nunca ha considerado, ni mucho menos, que las columnas hayan constituido, para él, publicaciones de segunda fila por el hecho de estar sometidas a una serie de condiciones dictadas por la precisión de las fechas y por la extensión, naturalmente reducida, del texto periodístico:

Sobra decir que, por definición, las columnas en su calidad de textos periodísticos no son capaces de provocar el mismo efecto [(que los textos narrativos)] [...] los textos columnísticos de Marías revelan sus vínculos, sus enlaces, sus paralelismos, sus repeticiones y sus variaciones, implícitos unas veces y otras explicitados por el autor. Añádase a ello que, a pesar de lo que el género casi impone, la temática del columnismo de Marías apenas tiene fecha de caducidad y se puede concluir sin ambages que también las columnas participan en la intrincada batalla con y contra el tiempo [...] librada por un autor que se empeña en convertirse en un fantasma literario con una pasión, una dedicación, una inteligencia, una honradez y una inventiva tan excepcionales como entrañables (Steenmeijer, 2006, p. 95).

Sus reflexiones sobre el lenguaje han conducido a Javier Marías a analizar la creación literaria propia y su discurso de ingreso en la Real Academia Española constituye una buena muestra de ello ya que su título es Sobre la dificultad de contar (2008). Asimismo, se interesa mucho por el proceso de traducción, especialmente del inglés al español pues, además de otras obras importantes, cabe destacar su versión española del complejo texto de Laurence Stern The Life and Opinions of Tristram Shandy, Gentleman (1760-1767). La traducción de Javier Marías se publicó en 1979 y obtuvo el Premio Nacional de Traducción de dicho año. Posteriormente, en 2012, se publicó una segunda edición revisada.

Como es sabido, Javier Marías es columnista habitual en diferentes rotativos, se ocupa de temas diversos relacionados con la actualidad social y cultural y muchas de sus columnas tratan temas relacionados con el uso del lenguaje. La mayor parte

${ }^{3} \mathrm{http}: /$ hemerotecadigital.bne.es/details.vm?q=id:0002220089\&lang=es 
de sus colaboraciones de este tipo se han publicado agrupadas en un volumen de 2012 titulado Lección pasada de moda editado por Alexis Grohman, uno de los principales estudiosos de la obra del escritor.

Señala Grohmann en su prólogo que Marías parece poseer una voluntad interventora sobre la lengua derivada de su interés por el lenguaje desde la perspectiva de la creación literaria y de la traducción. Sigue indicando que las posiciones de Marías no son extremas puesto que es consciente de que el lenguaje cambia con el paso del tiempo aunque piensa que la lengua debe cuidarse para que sea, siempre, un vehículo eficaz para la comunicación:

No cabe duda de que a Javier Marías se le impone una voluntad interventora hacia el idioma [...] Sus textos nacieron [...] como un desahogo ante rasgos que deterioran nuestro sistema de comunicación. Así cobra forma la postura de que el hombre tiene deberes inexcusables, mandatorios, con su idioma en todo momento [...] no es lícito adoptar una posición de indiferencia o de inhibición hacia la lengua. Javier Marías se inscribe de ese modo en la tradición de quienes han creído necesario ventilar públicamente este orden de cuestiones, de librar un cuerpo a cuerpo sin el cual la vida cultural de un país no sería normal [...] (Grohman, 2012, p. 8).

El corpus de columnas sobre el lenguaje contenido en Lección pasada de moda comprende 49 colaboraciones que Alexis Grohman agrupa, en su antología, en función de los temas con el objetivo de proporcionar al lector una perspectiva de las ideas del escritor sobre determinados aspectos del lenguaje. Como puede verse en la Tabla 2, en este estudio se ha preferido el criterio temporal para presentar este corpus, en parte para facilitar la comparación con el corpus de columnas de Fernando Araujo y, en parte, porque la cronología revela también los intereses del autor en función del paso del tiempo.

Se ha añadido, en la Tabla 2, una columna titulada "tema" que no figura en la presentación de las columnas de Araujo. Como se puede apreciar, los títulos de las colaboraciones del autor salmantino son transparentes con respecto al tema que en ellas se aborda. En el caso del escritor, en cambio, no existe tal transparencia y son poco informativos a este respecto. Por ello, se ha optado por añadir esta información que facilita la visión temática del conjunto de las colaboraciones lingüísticas de Javier Marías como puede verse en la Tabla 2 del apéndice.

A la vista de los títulos y temas de estas columnas queda claramente de manifiesto que Fernando Araujo y Javier Marías comparten, más allá de la distancia temporal, las mismas preocupaciones sobre la corrección lingüística y la supuesta "corrupción" de la lengua. En el siguiente apartado, y a partir del análisis de los dos corpus, se intentará dar respuesta a las tres preguntas que se han planteado al final de la Introducción de este trabajo.

\section{Los temas tratados por Fernando Araujo y Javier Marías}

La comparación de las columnas de los dos autores muestra que sus contribuciones pueden dividirse en dos categorías: aquellas que tratan cuestiones que son de actualidad en sus dos épocas y aquellas que están más ligadas al contexto cultural de cada uno de ellos.

Constituyen un buen ejemplo de la primera categoría las colaboraciones de ambos sobre los usos de "deber" y "deber de": Araujo escribe sobre esta cuestión en 1912 y Marías lo hace en 2009 para decir prácticamente lo mismo: 
1) [...] en su deseo de armonizar las cosas para salvar los dos giros, los gramáticos hallaron cierta diferencia de sentido entre deber, seguido de lo que ellos llaman un infinitivo y deber de en la misma posición. La diferencia, en efecto, salta a la vista en algunos casos: entre "cada día voy entendiendo más lo que debe ser un alma ante Dios", y "yo soy amiga de apretar mucho en las virtudes, mas no en el rigor; debe de ser, ser yo poco penitente", frases ambas de Santa Teresa, bien se ve el valor absoluto del primer debe ser, y el valor precario, dubitativo, de conjetura, del segundo debe de ser.

Fundados en esta diferencia han establecido, y la Academia llegó a consagrarlo, el uso del deber de ser en el sentido de obligación dudosa, de presunción, de posibilidad, debiéndose suprimir el de en los demás casos. Es una transacción para salvar ambos giros, que jamás ha sido observada por los buenos escritores ni menos por los del montón; los que tienen costumbre de poner el de, lo ponen, y los que no, prescinden de él, trátese o no de sentido dubitativo. Hay que tener convicciones en materia de lenguaje, como en política y como en todo (Araujo, abril 1912, n. ${ }^{\circ} 280$ ).

2) Hace ya años que algunos lectores me han acusado de recurrir a verbo "deber" para expresar una inferencia, ignorando que, así como nunca puede decirse "deber de" para lo imperativo (esa es precisamente la fórmula para la inferencia: "debe de haberle sentado algo mal", y jamás "el Gobierno debe de atender nuestras peticiones", como sueltan casi todos los políticos y locutores), sí puede decirse "deber" a secas para las suposiciones: "debe ser amigo suyo" es correcto, y yo a veces, por una cuestión silábica y de ritmo de la prosa he omitido el "de" en teoría preceptivo en estos casos. Es una opción, no una incorrección (Marías, 2012, p. 41).

Nótese que Araujo y Marías se refieren en primer lugar a la "doctrina oficial" sobre los usos de "deber" y "deber de" para comentar después los usos contemporáneos. Que dos columnistas se refieran a la misma cuestión con un siglo de diferencia indica que no está resuelta en el uso a pesar de los años transcurridos. $\mathrm{Y}$ es interesante señalar la última frase de las dos citas: Araujo se refiere al comportamiento de quienes escriben y Marías habla desde la perspectiva del escritor que toma decisiones estilísticas sobre su forma de usar la lengua y en ambos comentarios se trasluce que no es un tema cerrado.

Otro aspecto que preocupa a ambos autores es el del supuesto mal uso de la lengua por parte de los políticos. Ello se aprecia también en los títulos y temas de sus columnas (Tabla 1: "La lengua parlamentaria" o "Gazapos y planchas", por ejemplo; Tabla 2: "Brutta e povera Italia" o "Ventajas de la zafiedad reinante") y puede verse también, a continuación, en los siguientes ejemplos:

3) No puede dudarse que existe una lengua parlamentaria. Cada grupo social tiene su vocabulario y su sintaxis, y el Parlamento no podía prescindir de tener los suyos. No es nuestro objeto estudiar las causas de la existencia ni de las evoluciones de esta lengua, sino examinar la transformación que sufren, en boca de los políticos, las frases de la lengua usual. Es indudable que los políticos son extremadamente ignorantes de la lengua nacional; si hablan de todo sin saber de nada, tienden, sin poderlo remediar, á decirlo todo incorrectamente: voces apartadas de su propia significación, frases, perífrasis y metáforas desordenadas é incoherentes, incorrecciones tradicionales que el parlamentario joven copia del viejo: tales son los elementos típicos de la lengua parlamentaria, no ya de la empleada por oradores sin relieve, sino de la que emplean los políticos más ilustres [...] (Araujo, 1901, n. ${ }^{\circ} 149$ ).

4) A todos nuestros Gobiernos [...] se les llena e inflama la boca cada vez que entonan cánticos a la lengua española [...]. Las frecuentes proclamas en exaltación del español son vacuas, más bien grotescas, e insoportables de tan trilladas [...].

Lo más ridículo es, sin embargo, que junto a estas pomposidades oficiales, nuestros Gobiernos llevan decenios procurando que esa alabada lengua desaparezca de aquí, o quede reducida a un mejunje de letras, a un penoso rudimento, a un balbuceo, a algo casi inarticulado y de sonrojante primitivismo (Marías, 2012, p. 4). 
Así, al igual que en el caso de "deber" y "deber de", es esta una cuestión que no parece que el paso del tiempo haya cambiado. Los dos columnistas se quejan de lo mismo, de tener que escuchar o leer a políticos "ignorantes" que tienden a "decirlo todo incorrectamente" (Araujo), o que convierten la lengua en un algo "inarticulado" y "primitivo" (Marías).

Ambos autores se han ocupado también en sus columnas de la repercusión que tiene la traducción sobre las lenguas a las que se versiona porque ello propicia la entrada en ellas de elementos procedentes del idioma desde el que se traduce. Así, por ejemplo, Fernando Araujo critica duramente en muchas de sus colaboraciones la penetración de galicismos en español a través de las traducciones (ver Tabla 1). No es de extrañar puesto que, en el siglo XIX, se traducía al español especialmente desde el francés y, por tanto, el autor veía como una "corrupción" la incorporación al español de palabras procedentes de dicha lengua. Javier Marías, por su parte, se inquieta por los anglicismos procedentes de traducciones del inglés (ver Tabla 2), como corresponde a la segunda mitad del siglo XX y al siglo XXI, ya que la penetración de anglicismos en casi todas las demás lenguas es un hecho actualmente. Aunque ambos autores orienten sus críticas a neologismos procedentes de lenguas distintas, lo cual les liga a su contexto cultural, debe señalarse que comparten la misma preocupación: evitar la penetración en el español de elementos de otras lenguas a través de la traducción.

En cuanto a las diferencias en los problemas lingüísticos tratados, debe comentarse que los dos grandes temas, ligados a su propio contexto cultural, que abordan cada uno de los autores son la supuesta "corrupción" del español en América, en el caso de Fernando Araujo (véase Tabla 1), y el lenguaje "políticamente correcto" por parte de Javier Marías (véase Tabla 2).

La cuestión del español de América a finales del siglo XIX estaba ligada al problema de la unidad de la lengua, en estrecha dependencia de todas las cuestiones políticas y económicas derivadas de los procesos de independencia de los países latinoamericanos (Poch, 2018). Araujo, como no podía ser de otra forma dada su trayectoria fuertemente normativista, adopta la postura que defiende la unidad y critica abiertamente las innovaciones que progresivamente van apareciendo en el español de los países latinoamericanos que, a su juicio, pueden desembocar en una "rotura" del idioma:

5) Es realmente un dolor lo que sucede con el castellano en América. Y no se trata aquí de la cuestión de la introducción en nuestro idioma de americanismos propiamente dichos, ya se llamen nahuatlismos, ya paraguayismos, etc., pues esa introducción es legítima y plausible [...] Lo intolerable es la deformación del castellano por la introducción de galicismos, anglicismos, alemanismos y solecismos de todo género, vicio corriente en la Península misma [...] y que en las Repúblicas de Sur-América llega á extremos increïbles [...] una cosa es el crecimiento y desarrollo natural de una lengua, como el de un individuo, dentro de sus facultades y en armonía con sus proporciones, sus elementos constitutivos y su desenvolvimiento normal, y otra el crecimiento anormal, enfermizo y deformador por medio de diviesos y de jorobas, de excrescencias y de abotargamientos que le desfiguran y estropean (Araujo, 1908, n. $\left.{ }^{\circ} 240\right)$.

El paso de los años y las transformaciones en los ámbitos políticos, sociales y culturales han conducido al surgimiento del concepto de panhispanismo que impregna la visión actual de la lengua española y privilegia lo contrario de lo que criticaba Araujo: la riqueza de las variedades y el hecho de que la lengua puede ser 
única respetando todas las variaciones geográficas y sociales. Por tanto, este problema es inexistente en la prensa actual y, en el siglo XXI, las distintas colaboraciones que se ocupan del español en América tienden a abundar en la perspectiva panhispánica.

La cuestión del "lenguaje políticamente correcto" es una constante en las columnas de Javier Marías que se refiere al tema negativamente y con gran contundencia:

6) Ya hablé hace semanas de los vigilantes reiterativos del "todos y todas", y hoy mismo he visto a un político vasco [...] incluirse ridículamente en un fenómeno esquizofrénico, al decir "Y así nosotros, y así nosotras ...."...] Pero también están [...] los que nos instan a no utilizar nunca términos en sí mismos inocuos pero que ellos han tildado de "peyorativos" o "discriminatorios": decir de alguien que es "negro" no difiere apenas de decir que es "rubio", algo meramente descriptivo [...] condenar "gordo" al ostracismo equivale a desterrar "flaco", "alto" o "bajo", y así hasta el infinito. Hay quienes defienden estas erradicaciones con el argumento de que cada colectivo tiene derecho a decidir cómo quiere llamarse. $Y$ en efecto así es, pero no sólo cada colectivo, sino cada individuo; a lo que en cambio no lo tienen ni unos ni otros es a decidir cómo los demás hemos de llamarlos, esto es, a imponérnoslo (Marías, 2012, p. 35).

Esta preocupación no existía en la época de Fernando Araujo, pero es de rabiosa actualidad en el siglo XXI, y el lenguaje "políticamente correcto" tiene actualmente sus defensores y sus detractores que defienden encendidamente sus posiciones como puede verse fácilmente en toda la prensa. Visto lo ocurrido con el tema de la posible "rotura del español" a finales del siglo XIX, es inevitable preguntarse hoy en día cómo será el español dentro de unas décadas: si la corrección política habrá ganado la batalla o si caerá en desuso como otras modas que en determinados momentos parecía que se convertirían en usos generalizados. Es este un buen ejemplo de los problemas lingüísticos que generan polémicas hoy en día y que los lectores siguen con atención.

La estructura del edificio constituido por la lengua ha resistido, por tanto, los embates de determinadas cuestiones sin resquebrajarse a pesar de los temas que no están cerrados: los pilares de la lengua que constituyen las columnas intentan, en estos casos, calzar el edificio para estabilizarlo. En cambio, frente a otras cuestiones más ancladas en un contexto social y cultural, las columnas han defendido posiciones que la propia evolución de la sociedad ha hecho que dejaran de constituir un problema.

\section{La posición de Fernando Araujo y de Javier Marías ante los usos lingüísticos}

Como se ha señalado en la Introducción, Carmen Marimon (2019a) apunta que las columnas sobre la lengua critican los usos de los contemporáneos del columnista (sea de la época que sea) en nombre de un modelo de español que existe en su imaginario:

Esto es lo que [...] les ocurre a los columnistas. En un momento especialmente vigoroso y rápido de la historia eligen manejar un concepto de norma anclado en un pasado prestigioso pero totalmente desvinculado del mundo real. Consecuencia de esa toma de postura ideológica es la construcción de un imaginario sobre la lengua independiente de la realidad social, plagado de amenazas catastrofistas [...] Muestran la existencia de un imaginario purista y conservador que argumenta contra el cambio en cualquiera de sus manifestaciones. Olvidan la idea de que el discurso solo vive en 
sociedad, que la norma es social poer definición, y por eso se equivocan en sus juicios (Marimón, 2019a, p. 32).

El caso de la crítica al lenguaje de los políticos que se ha mencionado en el apartado anterior constituye un buen ejemplo de ello pues para Araujo los políticos "actuales", sus contemporáneos, "tienden a decirlo todo incorrectamente" y para Marías los políticos del siglo XXI llevan decenios convirtiendo la lengua "en un balbuceo inarticulado y de sonrojante primitivismo". Por tanto, los predecesores de los políticos actuales, los que supuestamente manejaban bien la lengua, según Marías, eran los contemporáneos de Araujo. Pero para este autor, los políticos contemporáneos lo decían todo incorrectamente. Parece confirmarse así la tesis de Marimón (2019a) acerca del choque entre imaginarios. Tanto Araujo como Marías se refieren a un supuesto estadio de la lengua, anterior a ellos, en el que los políticos se expresaban "bien". No obstante, la cronología no aboga por la existencia de ese período de esplendor, sino que, al contrario, demuestra que es imposible su existencia.

Las dos citas de Fernando Araujo que figuran a continuación muestran la visión del autor de la degradación a la que, a sus ojos, está sometida la lengua española, una degradación que viene de antiguo, como señala explícitamente en la segunda cita, y que, de continuar, destrozará la lengua.

7) Pase que en la sección telegràfica de los periódicos, redactada á escape y corregida de cualquier modo, se deslicen disparates de Geografía y de Gramática; pase que á los traductores de folletines, mal pagados, no se les pida documentación alguna literaria, y se les autorice para destrozar los originales; pase que periódicos de escasos recursos tengan redactores sin cultura que se metan á mansalva por el campo de las letras, y no dejen títere con cabeza en su brutal espigueo; pase que en una gacetilla de reclamo se deje al anunciante plena libertad de atropellar la lengua que usa, pues para eso paga; pero que en periódicos de gran circulación, de inagotables recursos, de redacción bien montada y de prestigio bien adquirido se atente contra el castellano, y no en la sección telegráfica, ni en la de reclamos, ni en la de noticias, ni siquiera en la parlamentaria, sino en sendos artículos firmados, se maltrate la lengua nacional con la mayor frescura, eso no puede pasar, y no debe pasar, sin nuestra protesta al menos (Araujo, 1908, n. ${ }^{\circ}$ 229).

8) Las señoras y caballeros, pollos y pollas de la aristocracia,de la artesanía y del pueblo [...] coinciden en el punto concreto del mal empleo de Iosadjetivos encomiásticos y despreciativos, y sobre todo, de los superlativos, diciendo á veces verdaderas atrocidades, alterando el significado de las palabras y produciendo el desgaste de los vocablos de tal modo que, si las cosas siguen por el camino que llevan, no tardaremos en vernos en grave apuro para poder aplicar un calificativo con exactitud [...] Todo esto constituye una degradación, $i$ la que interesa poner coto para no falsear ni empobrecer la lengua. Ya decía Horacio que «multa renascentur quae jam ceciderunt, cadentque -quae nunc sunt in honore vocabula, si volet usus- quem penes arbitrium est, et jus, et norma loquendi»; lo que prueba que el mal es antiguo y que todas las lenguas lo padecen; però no por eso deja de ser mal, y debemos hacer lo posible para contener los progresos del que indicamos (Araujo, 1909, n. ${ }^{\circ} 250$ ).

Javier Marías, por su parte, apunta en la misma dirección cuando se refiere a palabras que caen en el desuso porque ya casi nadie entiende, o bien cuando se refiere a determinadas formas gramaticales cuyo uso se confunde con respecto al original de forma que pierden su significado cuando las emplean los hablantes contemporáneos del columnista como se puede apreciar en las siguientes citas: 
9) Algo va mal en una lengua cuando no sólo caen en desuso centenares de palabras que ya casi nadie entiende, sino también algunas formas básicas de la gramática y por lo tanto del habla, o bien se confunden "donde" y "cuando", lo cual viene a ser confundir el espacio con el tiempo [...] Pero peor y más lamentable es la casi absoluta desaparición de "cuyo", forma fundamental de cualquier lengua evolucionada y que heredamos del latín hace muchos siglos (Marías, 2012, p. 19).

10) ¿Qué nos ocurre con la lengua? Por una parte, ante el éxito de las ediciones de la Real Academia y otras, y en particular del Diccionario panhispánico de dudas [...], uno diría que hay una preocupación creciente por hablar y escribir bien y saber qué puede y conviene decirse. Por otra, en cambio, resulta evidente que la lengua se va pareciendo cada vez más a un magma informe del cual se puede extraer cualquier combinación, que la mayoría encontrará aceptable -o indiferente- por disparatada, vacía o carente de sentido que sea (Marías, 2012, p. 69).

El hecho de que columnistas que escriben en épocas diferentes se ocupen exactamente de los mismos temas y mantengan posturas idénticas en cuanto a la corrección y a la pureza de la lengua debería ser motivo de reflexión sobre las tensiones que se producen en el seno del edificio, en el seno de la estructura lingüística: los usos van siempre por delante, quienes se erigen en pilares de la lengua intentan frenar las transformaciones pero el paso del tiempo acaba mostrando que los hablantes consiguen transformar el edificio sin que tiemblen sus paredes maestras. Por tanto, las columnas sobre la lengua se revelan como un importante material portador de información sobre las tensiones que soporta la estructura del sistema, tensiones que logra superar sin que se resquebraje el edificio.

\section{El tono del discurso argumentativo de Fernando Araujo y Javier Marías}

Como se desprende ya de las citas que se han comentado hasta ahora de los dos autores estudiados, uno de los aspectos más significativos de su discurso argumentativo es su tono, la virulencia con la que defienden sus puntos de vista y con la que critican o directamente atacan a todos aquellos que, desde su perspectiva, atropellan el lenguaje por diversos motivos. A continuación, se aportan dos claros ejemplos de este tono tan agresivo que les caracteriza:

11) En el estado de fiebre en que hay que redactar, componer, corregir y tirar los grandes diarios, no es extraño que se cometan deslices de más o menos bulto, incorrecciones de más ó menos gravedad y erratas de mayor o menor cuantía. Dejamos a un lado todas estas minucias, salvadas por la inteligencia de los lectores avisados, e inocentes desde luego por su origen. Pero lo que no puede ni debe pasar es la incorrección que arranca de la incultura, el desliz que revela ignorancia; quienes lo cometen incurren en confesión, de incompetencia periodística y deben ser licenciados en toda redacción que estime en algo su crédito (Araujo, 1912, n. ${ }^{\circ} 282$ ).

12) Confieso que me irrita particularmente el defecto que algunos intentan hacer pasar por madrileñista, consistente en maltratar nuestra $-d$ final convirtiéndola en $z$ : "Madriz", "ciudaz", "libertaz" y así. En un andaluz es del todo admisible que diga "Madrí" como en un catalán "Madrit", pero esa $z$ bestial no pertenece a ninguna pronunciación local -se lo aseguro a ustedes, y soy de Chamberí--, sino a una incapacidad para la ' $-d$ suave o relajada que corresponde (Marías, 2012, p. 57).

Fernando Araujo, como en otras ocasiones, lanza dardos envenenados contra quienes cometen desmanes lingüísticos. Sus ataques son frontales, directos y provocadores, su tono es fuertemente agresivo. Javier Marías, por su parte, 
argumenta de forma parecida pues sus afirmaciones son extraordinariamente tajantes como lo muestra el calificativo de "bestial" aplicado a la pronunciación de la consonante fricativa interdental en posición final de palabra. Debe notarse también que es común a los dos autores no aportar argumentos científicos que demuestren sus afirmaciones, sino que opinan como si estuvieran en posesión de la verdad de la corrección y del poder de sancionar a quienes no ajusten su uso de la lengua a la postura normativa por ellos defendida.

Probablemente el tono empleado es expresamente buscado tanto por Araujo como por Marías. Como se ha apuntado ya, los columnistas funcionan como pilares de la lengua, es decir, ayudan a apuntalar el edificio y el medio que utilizan para llegar a los hablantes es la prensa. El público lector está siempre atento a las cuestiones del "bien hablar" y, por tanto, uno de los recursos para crear polémica y captar la atención de todos los hablantes es la emisión de juicios contundentes que golpeen con fuerza la opinión pública y la sensibilicen hacia los errores y las incorrecciones para tratar de frenarlas y evitar así el supuesto proceso de degradación de la lengua. Por tanto, este tono virulento común debe entenderse como un recurso sabiamente dosificado para llamar la atención de los hablantes sobre las cuestiones lingüísticas. Debe señalarse también que la virulencia de los dos autores se expresa mediante recursos diferentes lo cual se corresponde con el perfil de los dos personajes. Mientras Fernando Araujo se lanza al embate frontal y directo, Javier Marías utiliza muchos más recursos expresivos, especialmente una punzante ironía, que son más propios de un escritor que de un periodista.

\section{Conclusión}

El análisis de los dos corpus de columnas lingüísticas estudiadas pone de relieve, una vez más, que este tipo de colaboraciones tiene en la prensa una larga tradición que viene del siglo XIX y que sigue viva, y sigue siendo potente, en el siglo XXI. El estudio de Fernando Araujo y Javier Marías ha mostrado también que en sus colaboraciones se tratan temas de usos lingüísticos idénticos con cien años de diferencia lo que significa que ciertos aspectos siguen sin estar resueltos. Ambos autores han mostrado también en sus columnas su preocupación por temas estrictamente ligados a su contexto social y cultural.

Fernando Araujo y Javier Marías sustentan posiciones similares en lo que respecta a la corrección lingüística pues ambos apelan a un estadio anterior de la lengua, un imaginario que está en la mente de los columnistas, en el cual los usos eran correctos. Frente a este hipotético estadio de esplendor, los usos contemporáneos hacen que los dos autores afirmen rotundamente que la lengua se encuentra en un claro proceso de degradación que debería poder detenerse para conservar la calidad de la expresión. Y para defender esta postura, Araujo y Marías recurren a un tono contundente, de abierta crítica, agresivo, en sus columnas para conseguir llamar la atención del público lector ante los problemas lingüísticos y adoptan así la función de pilares de la lengua pues su intención es defender los fundamentos de la estructura del edificio lingüístico desde una ideología determinada. 


\section{Referencias}

\section{Fuentes primarias}

1. Araujo, F. (1898-1914). Revista de Revistas. La España Moderna (1889-1914). Recuperado de: http://hemerotecadigital.bne.es/details.vm?q=id:0002220089\&lang=es

2. Marías, J. (2012). Lección pasada de moda. Barcelona, Galaxia Gutenberg.

\section{Fuentes secundarias}

1. Alcoba, S. (2018). Variaciones, norma y usos: las columnas sobre la lengua en España y en América: de Unamuno o Rosenblat y Moreno de Alba a Lázaro Carreter y Javier Marías. Seminario permanente de estudios sobre La norma lingüística del español, Huelva (2. ㄹ sesión). Recuperado de: https://www.academia.edu/42857275/

2. Asún, R. (1980). El proyecto cultural de La España Moderna y la literatura (1889-1914). Análisis de la revista y editorial. En Asún, R. Estudios y Ensayos (pp. 131-143). Alcalá de Henares, Universidad de Alcalá de Henares.

3. García García, J. M. (2014). Fernando Araujo. Un krausista salmantino. Salamanca, Diputación de Salamanca.

4. Grohmann, A. (2012). El hombre afrontando a la multitud. En Marías, J., Lección pasada de moda (pp. 9-28). Barcelona, Galaxia Gutenberg.

5. Lepinette, B. (2000). À propos de F. Araujo Gómez (1857-1914), auteur d'une grammaire historique pour l'enseignement du français aux espagnols (1889, 6. ${ }^{\mathrm{a}}$ ed., 1907). Essai de bio-bibliographie. En Casal, M. L. et al. (Eds.), La lingüística francesa en España camino del siglo XXI (Vol. 2, pp. 629-646). Santiago de Compostela, Universidad de Santiago de Compostela.

6. Lepinette, B. (2009). Eléments d'une dramaturgie épistémologique. Fernando Araujo (1857-1914), philologue et grammairien du français en Espagne. Synergies Espagne, 2, pp. 143-169.

7. Marías, J. (2008). Sobre la dificultad de contar. Discurso de Ingreso en la Real Academia de la Lengua. Recuperado de: http://www.javiermarias.es/discurso.pdf

8. Marimón, C. (2019a). Las columnas sobre la lengua, entre la norma lingüística y el uso real, en Poch, D. (Ed.). El español de Cataluña en los medios de comunicación (pp. 1536). Madrid-Frankfurt, Iberoamericana-Vervuert.

DOI: https://doi.org/10.31819/9783964568854-002

9. Marimón, C. (2019b). Introducción: Las Columnas sobre la lengua (CSL), un espacio discursivo para hablar de la lengua en la prensa. En Marimón Llorca, C. (Ed.), El columnismo lingüístico en España desde 1940. Análisis multidimensional y genérico (pp. 7-26). Madrid, Arco Libros.

10. Poch, D. (2015) La constitución de una disciplina científica: la fonética del español de Fernando Araujo (1894) a Tomás Navarro Tomás (1918). Actas del IX Congreso Internacional de Historia de la Lengua Española (Vol. 1, pp. 537-550). MadridFrankfurt, Iberoamericana-Vervuert.

DOI: https://doi.org/10.31819/9783964566492-026

11. Poch, D. (2018). El interés por el lenguaje en La España Moderna. En Amores, M. y Ferrús, B. (Eds.). 'La España Moderna', (1889-1914), Aproximaciones literarias y lingüisticas a una revista cultural (pp. 117-142). Madrid-Frankfurt, IberoamericanaVervuert. DOI: https://doi.org/10.31819/9783954877324-006

12. Steenmeijer, M. (2006). Javier Marías, columnista: el otro, el mismo. En Grohmann, A., Steenmeijer M. (Eds.). El columnismo de escritores españoles (1975-2005) (pp. 79-96). Madrid, Verbum. 


\section{Apéndice}

Tabla 1. Columnas de F. Araujo, publicadas en La España Moderna

\begin{tabular}{|c|c|}
\hline Mes / Año / Número & Título \\
\hline Agosto $1898 n^{\circ} 116$ & Los fonetistas \\
\hline Noviembre $1899 \mathrm{n}^{\circ} 119$ & $\begin{array}{l}\text { Tiquis miquis literarios: la patología en aumento o disminución: Jugar } \\
\text { toros }\end{array}$ \\
\hline Abril $1899 \mathrm{n}^{\circ} 124$ & Términos no parlamentarios \\
\hline Diciembre $1899 \mathrm{n}^{\circ} 132$ & Pronunciación de la palabra "boer" \\
\hline Febrero $1900 \mathrm{n}^{\circ} 134$ & El predominio de las lenguas \\
\hline Abril $1900 \mathrm{n}^{\circ} 136$ & El lenguaje de los monos \\
\hline Septiembre $1900 n^{\circ} 141$ & A propósito del lenguaje de los pájaros \\
\hline Septiembre $1900 \mathrm{n}^{\circ} 141$ & Lenguas y dialectos \\
\hline Noviembre $1900 n^{\circ} 143$ & Los regionalismos americanos y el idioma nacional \\
\hline Enero $1901 n^{\circ} 145$ & ¿Solecismo chileno? \\
\hline Marzo $1901 n^{\circ} 147$ & La lengua española en los Estados Unidos \\
\hline Mayo $1901 n^{\circ} 149$ & La lengua parlamentaria \\
\hline Julio $1901 \mathrm{n}^{\circ} 151$ & $\begin{array}{l}\text { Herejías literarias: verificador, guatear, pelerlinas, matelassés, } \\
\text { cupones, entrenar }\end{array}$ \\
\hline Abril $1902 \mathrm{n}^{\circ} 160$ & La lengua universal del porvenir \\
\hline Abril $1904 \mathrm{n}^{\circ} 184$ & La gramática en el siglo $X X$ \\
\hline Noviembre $1904 n^{\circ} 191$ & La lengua literaria contemporánea \\
\hline Marzo $1905 n^{\circ} 195$ & El latín, lengua universal \\
\hline Marzo $1905 n^{\circ} 195$ & La lengua universal \\
\hline Mayo $1905 n^{\circ} 197$ & La unidad de origen del lenguaje \\
\hline Diciembre $1905 n^{\circ} 204$ & Los clichés de la lengua \\
\hline Diciembre $1905 n^{\circ} 204$ & Origen de la palabra golfo \\
\hline $\begin{array}{l}\text { Febrero } 1906 n^{\circ} 206 \\
\text { Septiembre } 1906 n^{\circ} 213\end{array}$ & $\begin{array}{l}\text { El origen del lenguaje según la Biblia, la Filosofía y la Ciencia } \\
\text { Microbios del lenguaje }\end{array}$ \\
\hline Marzo $1907 n^{\circ} 219$ & Cómo se habla español en España \\
\hline Abril $1907 n^{\circ} 220$ & Las onomatopeyas \\
\hline Junio $1907 \mathrm{n}^{\circ} 222$ & Menudencias de aquí y de allá: Monsieur sud, verificadores \\
\hline Julio $1907 \mathrm{n}^{\circ} 223$ & $\begin{array}{l}\text { Menudencias de aquí y de allá: reprisse, reprisar, dillectantis y } \\
\text { kilogramo y análogas }\end{array}$ \\
\hline Agosto $1907 \mathrm{n}^{\circ} 224$ & $\begin{array}{l}\text { Menudencias de aquí y de allá: "no poder por menos", "estoy } \\
\text { ensimismado", autobús; omisión del artículo en los títulos }\end{array}$ \\
\hline Octubre $1907 n^{\circ} 226$ & "Orden del día" \\
\hline Octubre $1907 n^{\circ} 226$ & Deficit y superat \\
\hline Diciembre $1907 \mathrm{n}^{\circ} 228$ & "Las noticias acusan" \\
\hline Enero $1908 n^{\circ} 229$ & El método intuitivo en Lingüistica \\
\hline Enero $1908 n^{\circ} 229$ & Galicismos a granel \\
\hline Febrero 1908 n $^{\circ} 230$ & Otra vez acusar \\
\hline Marzo $1908 n^{\circ} 231$ & "Más” por "ya”, “mediana” y "un cierto" \\
\hline Marzo $1908 n^{\circ} 231$ & Pleonasmos risibles \\
\hline Marzo 1908 n $^{\circ} 231$ & La deformación de las palabras por la acentuación \\
\hline Abril $1908 n^{\circ} 232$ & ¿Análisis química o análisis químico? \\
\hline Abril $1908 n^{\circ} 232$ & Gimeno o Jimeno \\
\hline Mayo $1908 n^{\circ} 233$ & La imposibilidad de poder \\
\hline Mayo $1908 \mathrm{n}^{\circ} 233$ & ¿Arrivistas? o ¿arribistas? \\
\hline Noviembre 1908 n $^{\circ} 239$ & La deformación americana del castellano \\
\hline Noviembre $1908 n^{\circ} 240$ & La deformación del castellano en América \\
\hline Enero $1909 \mathrm{n}^{\circ} 241$ & Las glosolalias y su interpretación psicológica \\
\hline Marzo $1909 \mathrm{n}^{\circ} 243$ & Insistiendo: "Sud-expreso.", "verificadores" \\
\hline Abril $1909 \mathrm{n}^{\circ} 244$ & Galicismos en “miento" \\
\hline Julio $1909 n^{\circ} 247$ & ¿Verisimil o verosímil? \\
\hline Agosto $1909 n^{\circ} 248$ & Galicismos y gazapos \\
\hline Septiembre $1909 \mathrm{n}^{\circ} 249$ & Desarrollo y evolución del argot \\
\hline Septiembre 1909 n $^{\circ} 249$ & Americanismos \\
\hline Octubre $1909 \mathrm{n}^{\circ} 250$ & Transgresiones prosódicas \\
\hline Octubre $1909 \mathrm{n}^{\circ} 250$ & Degradación del superlativo \\
\hline
\end{tabular}




\begin{tabular}{|l|l|}
\hline Diciembre $1909 \mathrm{n}^{\circ} 252$ & Miles de formas ortográficas de un apellido \\
\hline Abril $1910 \mathrm{n}^{\circ} 256$ & "Importar" " "exportar" \\
Mayo $1910 \mathrm{n}^{\circ} 257$ & "Superlativos castellanos" \\
Mayo $1910 \mathrm{n}^{\circ} 257$ & "Adueñar, adueñamiento": empleo del pretérito" \\
Junio $1910 \mathrm{n}^{\circ} 258$ & El "Reina Mercedes" \\
Julio $1910 \mathrm{n}^{\circ} 259$ & "Ológrafo" \\
Diciembre $1910 \mathrm{n}^{\circ} 264$ & La palabra alemana "Kampf" (combate) " \\
Diciembre $1910 \mathrm{n}^{\circ} 264$ & "Benefactores", "naivamente" \\
\hline Enero $1911 \mathrm{n}^{\circ} 265$ & ¿Sintáxico ó sintáctico? \\
Abril $1911 \mathrm{n}^{\circ} 268$ & La fortuna de una palabra (déraciné, descastado) \\
Agosto $1911 \mathrm{n}^{\circ} 272$ & La palabra polipote \\
Septiembre $1911 \mathrm{n}^{\circ} 273$ & La lengua del caló (argot) \\
Octubre $1911 \mathrm{n}^{\circ} 274$ & La palabra felibre \\
Noviembre $1911 \mathrm{n}^{\circ} 275$ & Toaletas \\
\hline Abril $1912 \mathrm{n}^{\circ} 280$ & Más sobre deber de \\
Junio $1912 \mathrm{n}^{\circ} 282$ & Gazapos y planchas \\
\hline Febrero $1913 \mathrm{n}^{\circ} 290$ & Valor educativo de la Gramática \\
Marzo $1913 \mathrm{n}^{\circ} 291$ & Galicismo de sobre por de \\
\hline Mayo $1914 \mathrm{n}^{\circ} 305$ & Dando vueltas a los verificadores \\
\hline
\end{tabular}

Tabla 2. Columnas de J. Marías publicadas en Lección pasada de moda

\begin{tabular}{|c|c|c|}
\hline Fecha & Título & Tema \\
\hline $16-3-1987$ & De la actual dificultad de insultar & $\begin{array}{l}\text { Los insultos tradicionales han dejado de serlo y es muy difícil } \\
\text { insultar a alguien con términos directos }\end{array}$ \\
\hline $22-3-1991$ & Insultos y protestantismo & $\begin{array}{l}\text { Segunda parte del artículo anterior "De la actual dificultad de } \\
\text { insultar }\end{array}$ \\
\hline $12-3-1994$ & El habla intransferible & $\begin{array}{l}\text { Contra eufemismos igualitarios del lenguaje políticamente } \\
\text { correcto }\end{array}$ \\
\hline $20-3-1995$ & Cursilerías lingüisticas & Contra el concepto de lenguaje sexista \\
\hline $1-10-1995$ & Falseamiento y secuestro & $\begin{array}{l}\text { Contra el lenguaje políticamente correcto que altera los textos } \\
\text { originales }\end{array}$ \\
\hline $7-1-1996$ & $\begin{array}{l}\text { Breve y arbitraria guía estilística } \\
\text { para detectar farsantes }\end{array}$ & Expresiones o giros que el autor detesta \\
\hline $12-5-1996$ & Lección de lengua & Dificultades de traducción del término "killer" \\
\hline 6-10-1996 & Lección pasada de moda & Pronunciación de grupos consonánticos \\
\hline $5-1-1997$ & Para combatir una plaga & Contra los eufemismos \\
\hline $22-6-1997$ & $\begin{array}{l}\text { Breve y arbitraria guía } \\
\text { demográfica para detectar cursis }\end{array}$ & Contra expresiones cursis utilizadas por los escritores \\
\hline $31-8-1997$ & En desuso por abuso & Palabras usadas hasta la saciedad \\
\hline $21-12-1997$ & Escrupulosos racistas & Contra los eufemismos \\
\hline $25-1-1998$ & Cuyo estólido piafar & Sobre el uso de "cuyo" \\
\hline $26-7-1998$ & Don y daño de lenguas & Sobre creación y traducción \\
\hline $6-12-1998$ & Malas hablas & En México se habla muy bien y en España no \\
\hline $28-3-1999$ & Navío de recadero & "Bouc emissaire" vs "buque emisario" \\
\hline $9-5-1999$ & Nuestra o suya y mía & Contra Juan García Ponce sobre las variedades del español \\
\hline $14-5-2000$ & Doiches & $\begin{array}{l}\text { Relaciones entre política y lengua: la primera no debe imperar } \\
\text { sobre la segunda y desarrollar supuestos argumentos } \\
\text { científicos }\end{array}$ \\
\hline $13-8-2000$ & Todas las farsantas son igualas & Rechazo del concepto de lenguaje sexista \\
\hline $8-10-2000$ & Caballero de Mancha & $\begin{array}{l}\text { Contra Arturo Pérez Reverte por la ausencia de artículos ante } \\
\text { el nombre de determinados países }\end{array}$ \\
\hline $29-4-2001$ & Fastidiosos y muy embarazados & Falsos amigos \\
\hline $3-6-2001$ & Paridas o paridos & Contra el supuesto lenguaje no sexista \\
\hline $23-7-2001$ & Por la felicidad de los lectores & Malas traducciones \\
\hline $5-8-2001$ & Lo que se pone rancio & $\begin{array}{l}\text { Tópicos contemporáneos en los medios muy usados por los } \\
\text { políticos }\end{array}$ \\
\hline $2-9-2001$ & Su caucásico servidor & Contra los eufemismos políticamente correctos \\
\hline
\end{tabular}




\begin{tabular}{|c|c|c|}
\hline $25-11-2001$ & ¿Es usted el Santo Fantasma? & $\begin{array}{l}\text { Doblajes y subtítulos. El tratamiento de "usted" dirigido al } \\
\text { Rey }\end{array}$ \\
\hline $9-6-2002$ & $\begin{array}{l}\text { Un maravilloso manual de } \\
\text { fingimiento }\end{array}$ & Contra el lenguaje políticamente correcto \\
\hline $3-8-2003$ & La ley del balbuceo & Mal uso de la lengua por los políticos \\
\hline $21-3-2004$ & $\begin{array}{l}\text { Se colapsaron tributos } \\
\text { actualmente }\end{array}$ & Falsos amigos \\
\hline $13-3-2005$ & Productos podridos & Malas traducciones \\
\hline $24-4-2005$ & Exijo el último momento histórico & Mal uso de las palabras del título \\
\hline $17-7-2005$ & Nombrar o negar & El eufemismo que niega la realidad y no la nombra \\
\hline $18-9-2005$ & $\begin{array}{l}\text { Sablistas eclesiásticos y sablazos } \\
\text { gubernamentales }\end{array}$ & Sobre el uso de "sablazo" y "sablista" \\
\hline $30-10-2005$ & ¿Mande? & Malas traducciones \\
\hline $11-6-2006$ & Decir feamente nada & Contra los políticos que hablan y no dicen nada \\
\hline $10-12-2006$ & $\begin{array}{l}\text { Arbitrariedades de escritor } \\
\text { maniático }\end{array}$ & Tópicos contemporáneos que el autor detesta \\
\hline $17-12-2006$ & Narices con poco olfato & Contra el supuesto lenguaje no sexista \\
\hline $11-2-2007$ & Hundidos en una ciénaga & $\begin{array}{l}\text { Contra el lenguaje políticamente correcto y contra los errores } \\
\text { en el uso de muchas palabras }\end{array}$ \\
\hline $11-5-2008$ & No esperen por las mujeres & No se puede pedir a la RAE que suprima palabras \\
\hline $18-5-2008$ & Brutta e povera Italia & $\begin{array}{l}\text { Contra los políticos que hablan en público igual que en } \\
\text { privado }\end{array}$ \\
\hline $13-7-2008$ & El pelma ante los plastas & Contra el lenguaje no sexista \\
\hline $12-4-2009$ & Bachillerato con adultos & Contra los ignorantes que corrigen los usos correctos \\
\hline $8-11-2009$ & Que no me entero & Contra el lenguaje periodístico incomprensible \\
\hline $21-2-2010$ & Esa puta mierda & $\begin{array}{l}\text { Crítica a la forma de hablar de Esperanza Aguirre y a los } \\
\text { políticos del PP en general }\end{array}$ \\
\hline $5-12-2010$ & Ventajas de la zafiedad reinante & $\begin{array}{l}\text { Contra el lenguaje soez de los personajes públicos y de los } \\
\text { medios de comunicación }\end{array}$ \\
\hline $30-1-2011$ & Discusiones ortográficas $-I$ & Contra el uso de los acentos que propone RAE 2011 \\
\hline $6-2-2011$ & Discusiones ortográficas - II & Sobre el uso de las mayúsculas \\
\hline $13-2-2011$ & Isabel monta a Fernando & Contra el lenguaje no sexista \\
\hline $6-3-2011$ & Dos postdatas & $\begin{array}{l}\text { Sobre ortografía y pronunciación y análisis de la expresión } \\
\text { "en mi vida he fumado un solo cigarrillo" }\end{array}$ \\
\hline
\end{tabular}

